\title{
Matemática no Ensino Médio com um enfoque crítico: contribuições à formação de cidadãos
}

Vanessa Oechsler

Rosinéte Gaertner

\section{Resumo}

Os documentos que norteiam o Ensino Médio no Brasil, como a Lei de Diretrizes e Bases da Educação (LDB), os Parâmetros Curriculares Nacionais do Ensino Médio e as Orientações Curriculares para o Ensino Médio preconizam uma educação em que o estudante seja preparado para exercer seu papel de cidadão. Tendo em vista essa orientação, este artigo apresenta duas atividades, produto de uma dissertação de Mestrado Profissional, que abordam a Matemática, de forma a contribuir para o exercício da cidadania dos jovens. Essas propostas foram criadas a partir de uma pesquisa bibliográfica, em que foram estudados os documentos que norteiam o Ensino Médio, bem como a definição de cidadania e o movimento da Educação Matemática Crítica, que alia a ideia de cidadania com o ensino de Matemática.

Palavras-chave: Educação Matemática Crítica, Atividades de Matemática e Cidadania, Ensino Médio.

\section{Abstract \\ Math in High School with a Critical Focus: contributions to the formation of citizens}

The documents that guide High School in Brazil, as the Law of Education Guide lines and Bases(LDB), the National Curriculum Parameters and the Curriculum Guide lines for High School Education, advocate an education in which the student is prepared to play its role as a citizen. Toward this goal, this research presents two activities, developed in a Professional Masters Program, that address mathematics in order to contribute to the citizenship of young people. These proposal were created from literature search, in which we studied the documents that guide high school in Brazil, as well as the definition of citizenship and the movement of Critical Mathematics Education, which combines the idea of citizenship with the teaching of Mathematics.

Keywords: Critical Mathematics Education. Mathematics and CitizenshipActivities. High School.

\section{Abordando o ensino da matemática com um enfoque crítico}

Em 1996, a educação brasileira passou a ser norteada pela Lei № 9394, de 20 de dezembro de 1996, que estabeleceu as diretrizes e bases da educação nacional, sendo também conhecida 
como Lei de Diretrizes e Bases da Educação Nacional (LDB). Nesta lei, é definida a finalidade da educação básica (estruturada pela Educação Infantil, Ensino Fundamental e Ensino Médio): “[...] desenvolver o educando, assegurar-Ihe a formação comum indispensável para o exercício da cidadania e fornecer-Ihe meios para progredir no trabalho e em estudos posteriores." (BRASIL, 1996, art.22)

Tendo por pressuposto este artigo da LDB, os documentos oficiais do governo que norteiam o Ensino Médio, como os Parâmetros Curriculares Nacionais do Ensino Médio (PCNEM), as Orientações Curriculares Nacionais Complementares aos Parâmetros Curriculares Nacionais ( $\mathrm{PCN}+)$ e Orientações Curriculares para o Ensino Médio, apontam a necessidade de se desenvolver um ensino que propicie o exercício da cidadania aos estudantes.

Nos Parâmetros Curriculares Nacionais do Ensino Médio (PCNEM), cita-se a necessidade de se desenvolverem competências que auxiliem no exercício da cidadania.

"De que competências se está falando? Da capacidade de abstração, do desenvolvimento do pensamento sistêmico, ao contrário da compreensão parcial e fragmentada dos fenômenos, da criatividade, da curiosidade, da capacidade de pensar múltiplas alternativas para a solução de um problema, ou seja, do desenvolvimento do pensamento divergente, da capacidade de trabalhar em equipe, da disposição para procurar e aceitar críticas, da disposição para o risco, do desenvolvimento do pensamento crítico, do saber comunicar-se, da capacidade de buscar conhecimento. Estas são competências que devem estar presentes na esfera social, cultural, nas atividades políticas e sociais como um todo, e que são condições para o exercício da cidadania num contexto democrático." (BRASIL, 2000, p.11 e 12)

Especificamente, na área de matemática, o documento destaca que o Ensino Médio deve ter um caráter de formação cidadã e não somente de formação de estudantes voltada para o mercado de trabalho.

Nas Orientações Curriculares Nacionais Complementares aos Parâmetros Curriculares Nacionais $(\mathrm{PCN}+)$, ressalta-se que o cidadão precisa ter outras habilidades, como saber se comunicar, argumentar, agir, participar da sociedade de forma prática e solidária, ser capaz de elaborar críticas e propostas de melhorias, estar em constante aprendizado. Por esse motivo, recomenda-se um ensino que possa contemplar o desenvolvimento de todas essas competências e não apenas um ensino que enfoque a repetição de algoritmos e fórmulas para a resolução de problemas, muitas vezes, fora da realidade do estudante. Na Matemática, o documento aponta as seguintes competências a serem desenvolvidas pelo estudante para o exercício da cidadania: (i) representação e comunicação, o que envolve a leitura e a interpretação de textos que lhe são apresentados; (ex.: leitura de uma embalagem, um manual técnico, textos de jornais) (ii) 
investigação e compreensão, as quais estão vinculadas ao enfrentamento das situações-problema que Ihe são propostas; (iii) contextualização das ciências no âmbito sociocultural, o que implica realizar uma análise crítica das ideias e das questões que são apresentadas no mundo e pensar como o conhecimento científico pode auxiliar na transformação dessa sociedade.

As Orientações Curriculares para o Ensino Médio têm o intuito de aprofundar alguns pontos do PCNEM. Aponta-se que, para o exercício da cidadania, o estudante deve saber analisar um problema e tomar as decisões necessárias para a sua resolução. Para tanto, a metodologia de ensino precisa estar em consonância com essas ações, destacando o papel do professor como mediador do conhecimento e não apenas como expositor de conteúdos. Para uma educação voltada para a cidadania, o estudante não pode mais ser um agente passivo e receptivo; há necessidade que haja reflexão, além da ação, nas atividades propostas.

Observa-se, nos documentos citados anteriormente, que todos defendem uma educação voltada para o exercício da cidadania, sendo apontadas algumas ações para se atingir tal objetivo - fomentar a iniciativa (PCNEM) e incitar a reflexão sobre situações-problema (Orientações Curriculares). Entretanto, nesses documentos, não é apresentado referencial teórico que possa orientar o professor quanto à prática em sala de aula. Nesse sentido, para compreender o que os documentos apontam como "exercício da cidadania", é necessário que se entenda o significado dessa expressão. Para muitas pessoas, o ato de votar, de colocar a mão no lado esquerdo do peito ao cantar o hino nacional, o direito à saúde e à educação, a liberdade individual de ir e vir, a liberdade de imprensa são formas de exercer a cidadania. A definição do conceito de cidadania tem relação com todas essas considerações apontadas, mas não compreende somente essas ideias, sendo muito mais amplo do que esses atos e direitos.

O dicionário Houaiss da Língua Portuguesa (2009, p.463) conceitua cidadania como "condição de pessoa que, como membro de um Estado, se acha no gozo de direitos que lhe permitem participar da vida política." Dentro dessa percepção, é importante destacar que a cidadania é a condição de uma pessoa que é membro de um Estado, uma vez que, em cada Estado, os direitos e deveres podem ser distintos, o que implica atitudes cidadãs diferentes. 0 dicionário Oxford (2003) corrobora com essa ideia e descreve que, numa sociedade republicana, a cidadania está associada aos direitos e deveres particulares do cidadão e a um compromisso de igualdade entre esses indivíduos. Observa-se, nesses dois dicionários, que a conceituação de cidadania está atrelada aos direitos e deveres do cidadão.

O sociólogo britânico T. H. Marshall (1967, p.63) apresenta uma definição de cidadania que também envolve as ideias de direitos e deveres do indivíduo, ampliando um pouco mais esse conceito e dividindo-o em três partes: civil, política e social. A parte civil refere-se aos "[...] direitos necessários à liberdade individual - liberdade de ir e vir, liberdade de imprensa, pensamento e fé, o direito à propriedade e de concluir contratos válidos e o direito à justiça."; a política alude ao direito de participar do poder público como um membro político ou como um 
eleitor desses membros. Por fim, a parte social faz referência a "tudo o que vai desde o direito a um mínimo de bem-estar econômico e segurança ao direito de participar, por completo, na herança social e levar a vida de um ser civilizado de acordo com os padrões que prevalecem na sociedade." Para Marshall, as instituições que mais representam o aspecto social são o sistema educacional e os serviços sociais.

Tomando por base essa definição de cidadania, conclui-se que a educação e, especificamente, a Educação Matemática, pode auxiliar na formação de cidadãos, no momento em que contribua para tornar as pessoas críticas quanto ao que acontece ao seu redor, como por exemplo, a respeito da veracidade de uma pesquisa eleitoral, da presença de juros embutidos em prestações, da análise de embalagens e de textos de jornais, entre outros. Ou seja, a matemática pode auxiliar o indivíduo a refletir sobre os três aspectos do conceito de cidadania.

As ideias de exercício da cidadania e Educação Matemática são discutidas por Ole Skovsmose, professor dinamarquês, que alia a cidadania com o movimento da Educação Matemática Crítica.

Esse Movimento surgiu na década de 1980 e se preocupa com os aspectos políticos da Educação Matemática. Como axioma ${ }^{1}$ básico da Educação Crítica, Skovsmose (2001a, p.32) apresenta que "a educação não deve servir como reprodução passiva de relações sociais existentes e de relações de poder", ou seja, a ideia de ensinar a Matemática parte do pressuposto de que os conhecimentos adquiridos em sala de aula possam auxiliar na identificação dos problemas sociais, na avaliação desses problemas e na reação contra as desigualdades existentes, culminando em discussões e na transformação da sociedade.

Mas qual o significado da educação crítica difundida por esse movimento? Skovsmose (2001) discorre que, para responder a esse questionamento, é necessário, inicialmente, abordar o significado do termo crítica. Para ele,

\section{"[...] podemos dizer que crítica tem a ver com: 1) Investigação de condições} para a obtenção do conhecimento; 2) uma identificação dos problemas sociais e sua avaliação; e 3) uma reação as situações sociais problemáticas. Em outras palavras, o conceito de crítica indica demanda sobre auto-reflexões, reflexões e reações." (SKOVSMOSE, 2001, p. 101)

Concluindo a sua ideia de crítica e ampliando-a para a Educação Crítica, Skovsmose (2001, p.101) aponta que

"[...] para que a educação, tanto como prática quanto como pesquisa, seja crítica, ela deve discutir condições básicas para a obtenção do conhecimento,

\footnotetext{
${ }^{1}$ Norma admitida como princípio, que não precisa ser demonstrada.
}

R. B. E. C. T., vol 8, núm. 4, set-dez.2015 ISSN - 1982-873X

DOI: Em andamento. 
deve estar a par dos problemas sociais, das desigualdades, da supressão, etc., $e$ deve tentar fazer da educação uma força social progressivamente ativa. Uma educação crítica não pode ser um simples prolongamento da relação social existente. Não pode ser um acessório das desigualdades que prevalecem na sociedade. Para ser crítica, a educação deve reagir às contradições sociais."

Com base nessas ideias, é possível apontar que o papel da educação para a formação de cidadãos críticos, passa pela análise da sociedade em que este cidadão está inserido e por uma discussão profunda sobre as desigualdades existentes dessa sociedade.

Sobre essa questão, Pinheiro $(2005$, p.18) ressalta que o ensino de Matemática na escola não pode ser aquele em que o professor explica e o estudante acumula informações, vistas como algo pronto e acabado. Para a autora, com esse tipo de educação, "O senso crítico dificilmente é aguçado na tomada de decisões, na criação de estratégias e recursos de resolução dos problemas que envolvam ciência e tecnologia em conjunto com a sociedade." Esse tipo de educação não contribui com a educação para a cidadania tão defendida nos documentos oficiais, sendo necessário, portanto, rediscuti-la, pois o que se percebe em muitas escolas é que a Matemática ensinada não faz o estudante refletir sobre o que lhe é exposto. Muitas vezes, basta apenas que o estudante escolha a fórmula adequada para resolver o problema apresentado, sem discutir o porquê dessa estratégia e o porquê do resultado obtido. Tal forma de ação não faz parte do pressuposto da Educação Matemática Crítica apresentado anteriormente, em que a Matemática deve servir como ferramenta para discutir as questões existentes na sociedade na qual o indivíduo está inserido.

Para romper com essa educação acrítica, Skovsmose apresenta os seguintes passos para se refletir sobre o uso da Matemática na resolução de um problema:

"(1) usamos o algoritmo de maneira correta?

(2) usamos o algoritmo certo?

(3) Podemos confiar no resultado vindo desse algoritmo?

(4) Poderíamos ter prescindido de cálculos formais?

(5) Como o uso efetivo de um algoritmo (apropriado ou não) afeta um contexto especifico?

(6) Poderíamos ter desempenhado a avaliação de outro modo?" (Skovsmose, 2001b, p.92)

É importante destacar o item (3), em que se questiona se se pode confiar no resultado vindo do algoritmo escolhido. É essa reflexão que os estudantes precisam fazer em sala de aula. Após a resolução, é possível confiar na resposta obtida? Analisando ainda o item (5), esse resultado afeta um contexto específico? Se sim, de que forma o afeta: beneficiando-o ou 
prejudicando-o? Essas são as reflexões feitas por professores e estudantes comprometidos com uma proposta de educação crítica. E, para que essa reflexão comece a acontecer, é necessário que o professor de Matemática a incentive em suas aulas.

Entretanto, como já foi explicitado anteriormente, os documentos que norteiam a educação no país defendem um ensino que contribua para a formação de cidadãos, mas não apontam como o professor pode executar tal ação. Sabe-se que a falta de materiais didáticos que exemplifiquem como abordar o exercício da cidadania em sala de aula pode contribuir para que esse tipo de educação não seja implementado. A fim de contribuir para a questão da formação de cidadãos por meio do ensino da Matemática, são apresentadas a seguir algumas ideias de abordagem de atividades matemáticas que possam instigar nos estudantes a reflexão e o exercício da cidadania. Pretende-se que essas atividades possam servir como subsídio ao professor de Matemática que pretende abordar uma Educação Matemática Crítica em sala de aula e que, a partir desse material, o professor possa criar suas próprias atividades.

\section{Atividade de Matemática para o Ensino Médio com um enfoque crítico}

Na dissertação de mestrado" "O ensino da matemática com um enfoque crítico: formação de cidadãos" foram elaboradas atividades ${ }^{2}$ que pudessem servir como subsídio aos professores de Matemática na sua prática pedagógica, enquanto formadores de cidadãos. A ideia é que o professor possa tanto utilizar as atividades apresentadas, como ressignificá-las para estimular o exercício da cidadania dos estudantes.

As atividades organizadas na dissertação foram desenvolvidas com base nos referenciais de educação para a cidadania e Educação Matemática Crítica expostos anteriormente. Foram elaboradas tendo como foco duas perspectivas: (i) ressignificar as questões contidas em alguns livros didáticos de Ensino Médio, aprovados pelo Programa Nacional de Livros Didáticos (PNLD), e adotados nas escolas de Blumenau (SC) e (ii) criar atividades a partir de ideias de outros livros didáticos, revistas e informações de professores de Ensino Médio.

${ }^{1}$ Dissertação desenvolvida por Vanessa Oechsler no Programa de Pós Graduação em Ensino de Ciências e Matemática, da Universidade Regional de Blumenau, orientada pela profa Dra. Rosinéte Gaertner.

2 As atividades apresentadas neste artigo, bem como outras atividades elaboradas e ressignificadas encontram-se na dissertação de mestrado, disponível em http://proxy.furb.br/tede/tde arquivos/9/TDE-2012-03-29T093406Z-

754/Publico/Diss\%20Vanessa\%200chsler.pdf

DOI: Em andamento. 
Com relação às atividades elaboradas a partir dos livros didáticos adotados nas escolas, aponta-se a importância desse trabalho, pois eles apresentam inúmeros conceitos e conteúdos que podem ser explorados pelo professor para o exercício da cidadania. Muitas vezes, o livro didático é o único material em que o professor embasa as suas aulas e, por isso, surge a importância de conhecer as atividades contidas no mesmo e ressignificá-las. Mas, como fazer isso? É interessante que o professor, inicialmente, o explore e, a partir daí, identifique em quais conteúdos pode-se abordar a matemática de uma forma mais crítica. Geralmente, os livros didáticos não orientam o professor nos exercícios expostos, sobre como abordar a questão da cidadania ao trabalhá-los com os estudantes, mas é possível adaptar os exercícios e, através de algumas pesquisas (em jornais, revistas, internet, entre outros) aperfeiçoar a atividade. Além da exploração do livro didático, outros materiais podem ser consultados para elaborar novas propostas de atividades, como outros livros, revistas e jornais, etc.

Outra perspectiva da pesquisa é a abordagem de um tema de interesse da comunidade escolar em que possa ser abordado um conteúdo explorado naquela fase de ensino. Tal atitude corrobora com as ideias de Skovsmose (2001), que indica que a Matemática estudada em sala de aula deve contribuir para reflexões na comunidade em que o estudante está inserido.

Neste artigo são apresentadas duas atividades constantes na dissertação já referida. A primeira, extraída do livro didático "Matemática Completa - volume 1" , de José Ruy Giovanni e José Roberto Bonjorno, foi reformulada para abordar o exercício da cidadania. A segunda foi elaborada a partir de pesquisas no livro "Desastre de 2008 no Vale do Itajaí: água, gente e política", obra organizada por Beate Frank e Lucia Sevegnani.

\section{Atividade 1}

A atividade 1, intitulada "Proteção solar e função", aborda uma situação-problema proposta no livro didático, em que é necessário calcular o coeficiente de eficiência de um protetor solar. Com base nessa situação, sugere-se que o professor possa utilizá-la para discutir com os seus estudantes a importância do uso do protetor solar para a saúde.

Público alvo: estudantes do $1^{\circ}$ ano do Ensino Médio

Conteúdo: Função

Momento de abordagem: Após a abordagem da definição de função e sua lei de formação.

Objetivos: Calcular o grau de eficiência e o fator de proteção de um protetor solar através de sua lei de formação

Discutir a necessidade do uso do protetor solar

Refletir sobre os preços do protetor solar praticados no Brasil.

112 DOI: Em andamento.

R. Bras. de Ensino de C\&T 
Desenvolvimento da atividade:

- O professor deve solicitar que os estudantes resolvam a atividade 5 do livro "Matemática Completa - volume 1, 2a edição renovada, 2005" de José Ruy Giovanni e José Roberto Bonjorno,

"(UFES) Os raios ultravioleta B, abreviados por UVB, atingem camadas mais profundas da pele e causam, além da vermelhidão, a inibição da síntese de proteínas, das mitoses e várias outras alterações celulares. Esses raios são parcialmente bloqueados pela camada de ozônio: no entanto, com a diminuição dessa camada, a penetração dos raios UVB tem aumentado, o que gera uma elevação potencial da incidência de câncer de pele. O tempo que se pode ficar exposto ao sol sem sofrer queimaduras causadas por radiação ultravioleta pode ser calculado com base no fator de proteção solar (FPS), que é utilizado para a classificação dos filtros solares. O coeficiente de eficiência $E(x)$ de um creme protetor é dado por $E(x)=1-\frac{1}{x}$, sendo $x$ o fator de proteção solar (FPS) do creme. Camila quer um creme protetor cujo coeficiente de eficiência seja 12\% maior do que o de um creme com FPS igual a 8. Ela deve, portanto, adquirir um creme com FPS igual a:
a) 30
b) 35
c) 40
d) 45
e) $50^{\prime \prime}$

na página 138:

Para resolver esse problema, inicialmente é necessário calcular o grau de eficiência do creme com FPS igual a 8. Para isso, substitui-se o $x$ da função pelo número 8:

$$
E(x)=1-\frac{1}{x} \Rightarrow E(8)=1-\frac{1}{8} \Rightarrow E(8)=1-0,125=0,875 \text {. }
$$

Dessa forma, o grau de eficiência do creme com FPS igual a 8 é de $87,5 \%$

Calculando-se o FPS com eficiência $12 \%$ maior, tem-se:

$$
c=\frac{112 \cdot 87,5}{100} \Rightarrow c=\frac{9800}{100} \Rightarrow 98 \text {. }
$$

Então, o grau de eficiência deverá ser de 98\%. Calculando o FPS, tem-se:

$$
0,98=1-\frac{1}{x} \Rightarrow \frac{1}{x}=1-0,98 \Rightarrow \frac{1}{x}=0,02 \Rightarrow x=\frac{1}{0,02} \Rightarrow x=50
$$

Nesse caso, o creme com FPS 50 tem 98\% de eficiência na proteção contra os raios UVB.

Esta foi a atividade proposta no livro. O professor poderia solicitar que os estudantes resolvessem a atividade e apresentassem a resposta. No entanto, qual a reflexão cidadã que se fez durante o desenvolvimento da atividade? Até este momento, nenhuma. Foram feitos apenas cálculos matemáticos. A partir desse ponto, a atividade pode ser ressignificada, de modo que suscite a discussão e a reflexão cidadã. Para tanto, o professor poderá propor os seguintes procedimentos:

- Após a resolução do exercício, solicitar que os estudantes grafiquem a função apresentada no enunciado do problema. Depois da construção do gráfico, discutir o comportamento da função, analisando se um protetor solar pode ter $100 \%$ de eficiência.

DOI: Em andamento. 


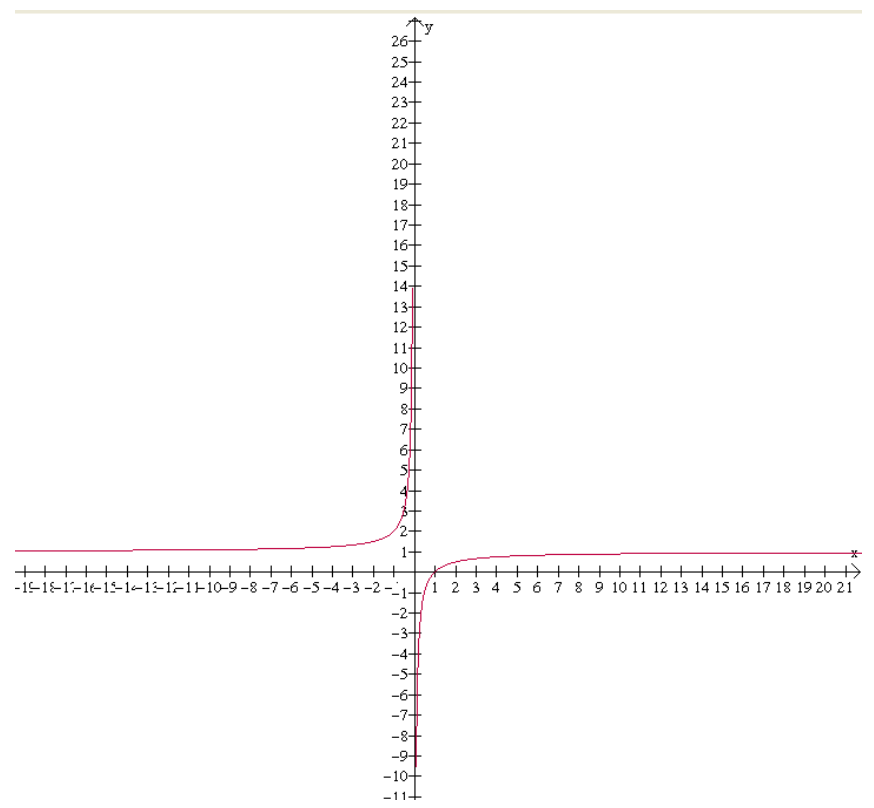

Gráfico 1: gráfico da função do grau de eficiência do protetor solar (do autor)

Com o gráfico desta função é possível verificar que nenhum protetor solar alcançará $100 \%$ de eficiência, pois o gráfico aproxima-se da reta $y=1$, mas não a toca. Dessa forma, a reta $y=1$ é a assíntota dessa função. Interpretando o problema, o grau de eficiência do protetor solar chegará muito próximo a 1, mas nunca será 1 , ou seja, não haverá grau de eficiência que seja $100 \%$.

É importante observar, nesse gráfico, o domínio e o contradomínio da função, poisesse problema não admite como resposta todos os números pertencentes ao conjunto dos Reais $(\mathbf{R})$. Analisando a função, tem-se que $x$ é o fator de proteção solar e, já que não existe um creme de proteção solar com fator de proteção solar nulo ou negativo, $x$ não pode admitir valores negativos e nulos. Como resposta a este problema, tem-se o grau de eficiência de um protetor solar, ou seja, qual a porcentagem de proteção que ele tem contra os raios UVB. Este grau de eficiência ficará entre os valores 0 e 1, pois, o protetor solar não será eficiente (0) ou terá valores de eficiência muito próximos de 1 (o que equivale a 100\%). Desta forma, a função $E(x)=1-\frac{1}{x}$ estará definida em $f: \aleph^{*} \rightarrow[0,1[$.

- Após essa discussão, o professor pode entregar um folheto com algumas indagações para que os estudantes pensem acerca da necessidade do uso do protetor solar. As informações contidas nesse folheto podem ser obtidas na internet. A seguir é apresentada uma ideia de folheto a ser entregue ao estudante para discussão: 
Agora que você resolveu o exercício de Proteção Solar e elaborou o gráfico da eficiência do protetor, conhecendo um pouco mais sobre como funciona o grau de proteção, vamos analisar mais algumas informações do Protetor Solar. Para isso:

a) Faça uma pesquisa em farmácias e supermercados da região e registre o preço dos protetores solares.

b) Após a pesquisa de preço, você deve ter percebido que existem diferenças entre o valor do produto e as marcas, bem como o valor do produto e o fator solar. Calcule a eficiência dos protetores solares pesquisados, utilizando a fórmula encontrada no exercício do livro. Qual dos produtos é mais vantajoso na compra?

c) Por que um produto tão importante à saúde é tão caro?

d) Qual a quantidade necessária de protetor solar?Observe o texto extraído abaixo de um site da internet:

"A quantidade ideal é de dois miligramas de protetor por centímetro quadrado". Essa definição é bem exata, mas pouco prática, não é mesmo? Se você não entendeu nada, calma, a dermatologista Carla Albuquerque traduz essa medida:

- Rosto e pescoço: 1 colher de chá;

- Tronco: 1 colher de sopa para a parte da frente e outra, para a parte de trás;

- Braços: 1 colher de sopa para ambos;

- Pernas: 1 colher de sopa para ambas.

* medidas válidas para um adulto de 1,70m, com peso entre 60 e $70 \mathrm{~kg}$.

Fonte:http://beleza.terra.com.br/mulher/interna/0,0I3352260-El7598,00-

Tire+duvidas+sobre+o+protetor+solar.html Acesso em: 14 jun. 2011

Estima-se que, para cada aplicação, um adulto gaste, em média, $20 \mathrm{ml}$ e, em dias em que as áreas expostas ao sol são menores, gaste, em média, $8 \mathrm{ml}$. Considerando que um frasco de protetor solar tenha $120 \mathrm{ml}$, por quantos dias o usuário pode utilizar o protetor, passando-o no corpo inteiro? E se passar apenas nas áreas mais expostas ao sol, quanto tempo durará o frasco?

e) Tomando por base o valor pesquisado no item "a" e a quantidade de protetor utilizada, quanto o usuário gastará em 1 ano, se utilizar o protetor apenas nas áreas mais expostas ao sol?

Nesta atividade, a matemática auxilia o estudante a perceber que existe um determinado ponto em que os fatores de proteção solar terão o mesmo efeito na proteção contra os raios UVB. Com esses cálculos, ele pode decidir qual a compra mais vantajosa a ser feita, levando em consideração o grau de eficiência do protetor e o seu valor. Além disso, a atividade tem como intuito gerar a discussão entre os estudantes sobre a necessidade do uso do protetor solar para prevenção de doenças e quais seriam as atitudes possíveis a serem tomadas para que esse produto se torne acessível a todos os cidadãos, uma vez que os índices de radiação aumentam a cada ano e os números de pessoas com câncer de pele também. 


\section{Atividade 2}

A atividade "Áreas interditadas após o deslizamento de 2008 e determinante" foi elaborada com base no livro Desastre de 2008 no Vale do Itajaí: água, gente e política, com o intuito de analisar a quantidade de terras na cidade de Blumenau que foram interditadas após os deslizamentos que assolaram a cidade em 2008 e que foram notícia em nível nacional. Esta atividade consiste em calcular, através de determinantes, a área de regiões interditadas para moradia no município de Blumenau e discutir com os estudantes a causa da ocupação irregular do solo.

Antes de abordar a atividade, convém situar o leitor sobre a situação enfrentada em 2008 em Blumenau e outros municípios (especialmente muitos do Vale do Itajaí). De acordo com Mattediet al (2009, p. 14)

"As chuvas intensas que se abateram sobre Santa Catarina em novembro de 2008, provocando escorregamentos, enxurradas e inundações, obrigaram 14 municípios a decretar estado de calamidade pública e 63 a decretar situação de emergência, o que demonstra a extensão do desastre que teve seus efeitos mais funestos concentrados no vale do Itajaí, nas regiões do médio vale e foz do rio Itajaí."

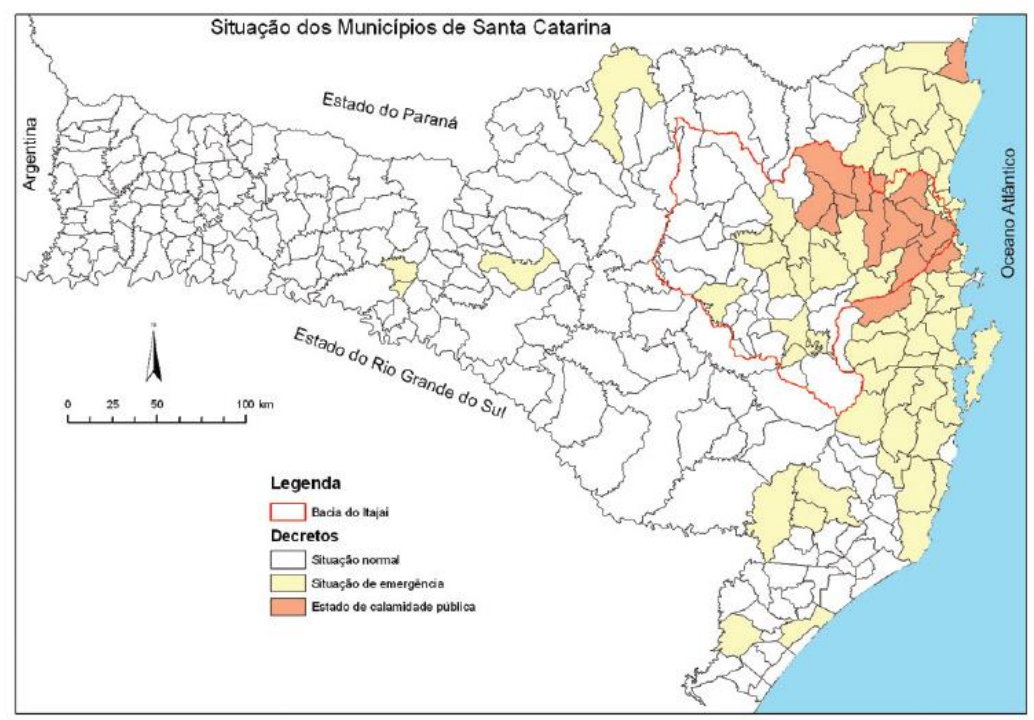

Figura 1: Distribuição dos municípios que decretaram situação de emergência e estado de calamidade pública em novembro de 2008.

(Fonte: Mattedi et. al. (2009, p.14))

O desastre de 2008 afetou cerca de 1,5 milhão de pessoas em Santa Catarina, sendo que 103 mil delas viviam na cidade de Blumenau. O desastre ainda resultou em um número de 135 mortos no estado. 
Em virtude da repercussão desse evento na mídia e na comunidade escolar, decidiu-se abordá-lo em sala de aula através do conteúdo matemático de determinantes. A discussão inicial foi o cálculo de locais interditados para construção na cidade de Blumenau, uma vez que após esse desastre em 2008 um estudo mais aprofundado sobre a geologia do município foi iniciado, com o intuito de evitar novos desastres como os vistos naquele ano.

A partir de agora, será apresentada a atividade desenvolvida para abordar esse tema.

Público alvo: estudantes da $2^{\circ}$ ano do Ensino Médio

Conteúdo: Determinante

Momento de abordagem: Após a discussão do conceito e do cálculo de determinantes.

Objetivos: Calcular o tamanho das áreas impróprias para construção na cidade de Blumenau.

Desenvolvimento da atividade: Discutir a respeito das causas da ocupação irregular e suas consequências.

- O professor entregará aos estudantes uma cópia do Anexo II do Decreto de Lei de Blumenau no 9853/2012, obtido no site www.blumenau.sc.gov.br, no link legislação. Este Decreto dispõe sobre as áreas com restrição de uso e ocupação do solo. Especificamente o anexo II contém o mapa do município de Blumenau com a descrição das áreas em estudo, áreas interditadas, com restrição e áreas liberadas para ocupação do solo.

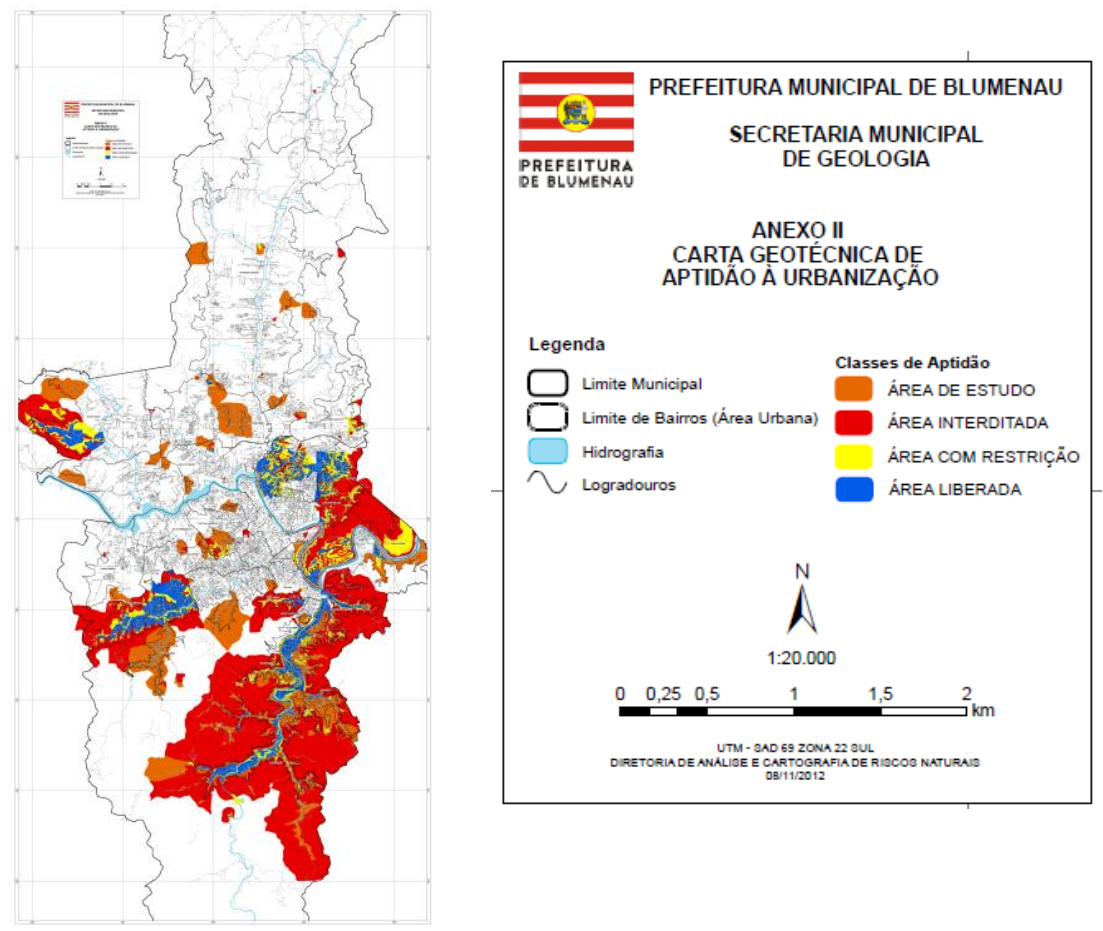

(Fonte: http://www.leismunicipais.com.br/cgi-local/showinglaw.pl) 
- Após a entrega do mapa, o professor deve analisá-lo com os estudantes:

a) O que significam as cores no mapa?

b) Qual a escala do mapa? O que significa essa escala?

Estas perguntas serão feitas para que os estudantes possam se familiarizar com o mapa entregue, entendendo a legenda apresentada.

Depois que os estudantes estiverem familiarizados com o mapa, o professor pode solicitar que eles marquem pontos nas intersecções dos eixos $x$ e y em algumas áreas do mapa, para calcular áreas interditadas, áreas em estudo, entre outros.

Para o cálculo dessas áreas, utiliza-se o cálculo do determinante. lezzi e Hazzan (2004) definem determinante da seguinte forma:

"Consideremos o conjunto das matrizes quadradas de elementos reais. Seja M uma matriz de ordem $n$ desse conjunto. Chamamos determinanteda matriz $M$ (e indicamos por det $M$ ) o número que podemos obter oprando com os elementos de $M$ da seguinte forma:

1ㅇ) Se $M$ é de ordem nJoice Luiza + Filipe Rossini $\left[a_{11}\right] \rightarrow \operatorname{det} M=a_{11}$ (...) $M=\left[\begin{array}{lll}a_{11} & a_{12} & a_{13} \\ a_{21} & a_{22} & a_{23} \\ a_{31} & a_{32} & a_{33}\end{array}\right]$, definimos
3o) Se $M$ é de ordem $n=3$, isto é,
$\operatorname{detM}=a_{11} \cdot a_{22} \cdot a_{33}+a_{12} \cdot a_{23} \cdot a_{31}+a_{13} \cdot a_{21} \cdot a_{32}-a_{13} \cdot a_{22} \cdot a_{31}+$
$-a_{11} \cdot a_{23} \cdot a_{32}-a_{12} \cdot a_{21} \cdot a_{33}$ (IEZZI; HAZAN, 2004, p.78-79)"

Pode-se utilizar o determinante para calcular a área de triângulos. Para explicar essa aplicação, Firer (s/d) explora a área de retângulo e triângulos, conforme figura 2: 


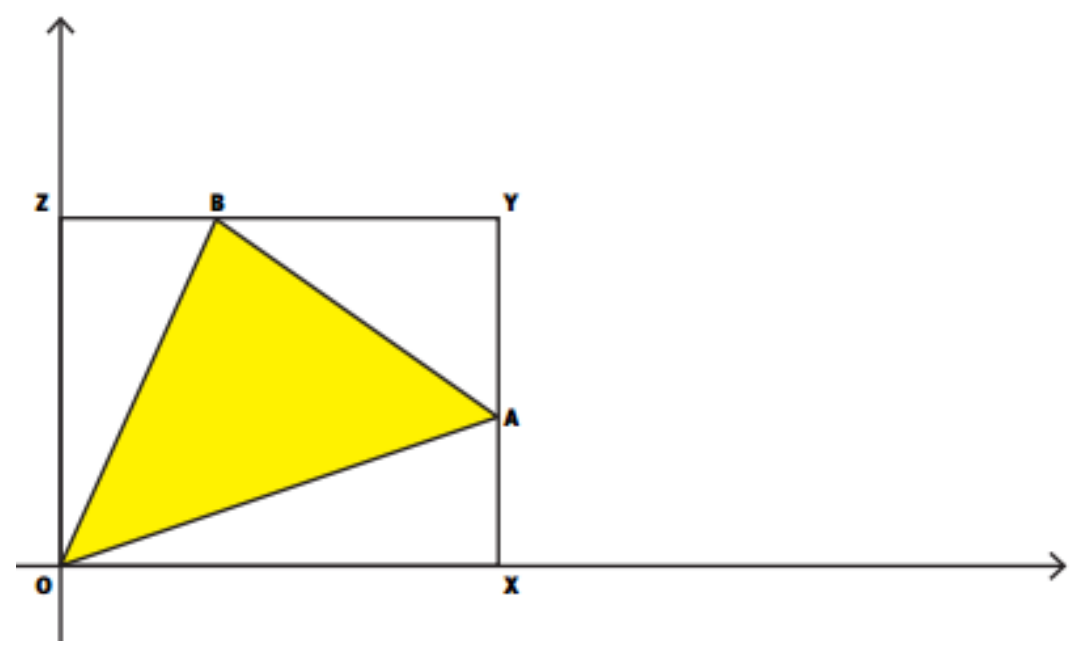

Figura 2: Ilustração que auxilia no cálculo da área de um triângulo

(Fonte: http://m3.ime.unicamp.br/recursos/1227)

Analisando a figura 2, tem-se o retângulo OXYZ, os triângulos retângulos OBZ, OXA e AYB e o triângulo OAB. Pode-se calcular a área da região colorida, de acordo com Firer (s/d) da seguinte forma:

$$
A_{O A B}=A_{O X Y Z}-A_{O B Z}-A_{O X A}-A_{A Y B}
$$

Sejam os pontos $A\left(a_{1}, a_{2}\right)$ e $B\left(b_{1}, b_{2}\right)$, pode-se calcular a área das figuras da seguinte forma:

$$
A_{O X Y Z}=a_{1} b_{2}, A_{O B Z}=\frac{b_{1} \cdot b_{2}}{2}, A_{O X A}=\frac{a_{1} \cdot a_{2}}{2} \text { e } A_{A Y B}=\frac{\left(b_{2}-a_{2}\right) \cdot\left(a_{1}-b_{1}\right)}{2}
$$

Calculando a área do triângulo $O A B$, tem-se:

$$
A_{O A B}=a_{1} \cdot b_{2}-\frac{b_{1} \cdot b_{2}}{2}-\frac{a_{1} \cdot a_{2}}{2}-\frac{\left(b_{2}-a_{2}\right) \cdot\left(a_{1}-b_{1}\right)}{2}
$$

Desenvolvendo a equação, tem-se:

$$
\begin{gathered}
A_{O A B}=a_{1} \cdot b_{2}-\frac{b_{1} \cdot b_{2}}{2}-\frac{a_{1} \cdot a_{2}}{2}-\frac{a_{1} b_{2}-b_{1} b_{2}-a_{1} a_{2}+a_{2} b_{1}}{2} \\
A_{O A B}=a_{1} b_{2}-\frac{b_{1} b_{2}}{2}-\frac{a_{1} a_{2}}{2}-\frac{a_{1} b_{2}}{2}+\frac{b_{1} b_{2}}{2}+\frac{a_{1} a_{2}}{2}-\frac{a_{2} b_{1}}{2} \\
A_{O A B}=a_{1} b_{2}-\frac{a_{1} b_{2}}{2}-\frac{a_{2} b_{1}}{2} \\
A_{O A B}=\frac{2 a_{1} b_{2}}{2}-\frac{a_{1} b_{2}}{2}-\frac{a_{2} b_{1}}{2} \\
A_{O A B}=\frac{a_{1} b_{2}}{2}-\frac{a_{2} b_{1}}{2}
\end{gathered}
$$

O que significa, em linguagem de determinante:

$$
A_{O A B}=\frac{1}{2} \operatorname{det}\left(\begin{array}{ll}
a_{1} & a_{2} \\
b_{1} & b_{2}
\end{array}\right)
$$

Para calcular a área de um triângulo por meio do determinane, as coordenadas dos pontos dos vértices desse triângulo depois são dispostos em uma matriz $D$, cujos elementos da última 
coluna sãosempre 1. O resultado do determinante dessa matriz deve ser multiplicado por $1 / 2$. Assim, encontra-se a área dessa região:

No entanto, essa fórmula é equivalente àqứela âpresentada anteriormente:

$$
\begin{aligned}
& A=\frac{1}{2} \operatorname{det}\left(\begin{array}{lll}
x_{a} & y_{a} & 1 \\
x_{b} & y_{b} & 1 \\
x_{0} & y_{1} & 1
\end{array}\right) \text { apresentada anteriormente: } \\
& \text { rea }=\frac{1}{2}\left(\operatorname{det}\left(\begin{array}{ll}
x_{a} & y_{a} \\
x_{b} & y_{b}
\end{array}\right)+\operatorname{det}\left(\begin{array}{ll}
x_{b} & y_{b} \\
x_{c} & y_{c}
\end{array}\right) \operatorname{det}\left(\begin{array}{ll}
x_{c} & y_{c} \\
x_{a} & y_{a}
\end{array}\right)\right)
\end{aligned}
$$

Calculando a área da região delimitada pelo triângulo, tem-se:

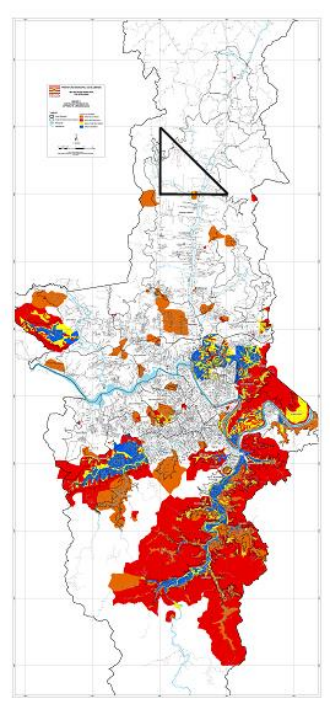

As coordenadas do vértice do triângulo, analisando-se o mapa são: (692000; 7040000), (692000; 7036000), (696000; 7036000)

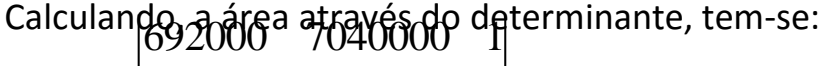

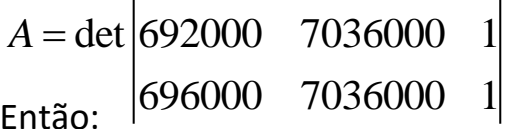

$$
A=\frac{1}{2} \cdot 16000000 \Rightarrow A=8000000 \text { u.a. }
$$

- Após o entendimento dos estudantes sobre a forma de calcular a área através do determinante, o professor pode pedir que eles marquem pontos aleatoriamente em áreas interditadas em estudo do mapa para calcular a área dessas regiões. É importante lembrar que, para fazer os cálculos, é necessário achar as coordenadas dos pontos, utilizando para isso, a escala do mapa, ao calcular as coordenadas dos pontos que não estão sobre os eixos.

- Após esse cálculo, o professor pode entregar aos estudantes o seguinte texto:

\section{OCUPAÇÃO DE ÁREAS DE RISCO}

A ocupação de áreas de risco de deslizamento, com edificações precárias, em sistema de autoconstrução, sem drenagem e com remoção da vegetação, tornou-se endêmica em Blumenau, e tem resultado em catástrofes periódicas nos períodos de maior precipitação. Em 1990, 22 pessoas perderam a vida, soterradas.

Na tragédia de novembro de 2008, foram 24 mortes. E na próxima tragédia? (SIEBERT, 2009, p. 49)

Fonte: SIEBERT, Claudia. (Des)controle urbano no vale do Itajaí. In: FRANK, Beate; SEVEGNANI, Lucia (orgs). Desastre de 2008 no vale do Itajaí. Água, gente e política. Blumenau: Agência de Água do Vale do Itajaí, 2009. p .38-51

- A partir desse texto, discutir com seus estudantes:

a) Você sabe quais os critérios levados em consideração para se mapear os locais de construção na cidade?

b) Por que existem pessoas que constroem casas em locais de risco? 
c) Quais as condições de saneamento, água, luz nas moradias desses locais de risco?

d) $\quad \mathrm{O}$ que as pessoas e o poder público devem fazer para impedir a construção em locais de risco?

Esta atividade pode ser ressignificada de acordo com os problemas enfrentados em cada região. Por exemplo, o determinante pode ser utilizado para o cálculo de área desmatada na Amazônia, para o cálculo de regiões áridas no país, entre outros. É interessante que as atividades exploradas estejam no cotidiano dos estudantes, como esta atividade sobre as áreas interditadas fez parte dos problemas enfrentados por muitos estudantes da região.

A aplicação destas atividades em sala de aula foi incentivada por meio de um curso $^{1}$ ministrado em 2011, para professores de Matemática e licenciandos em Matemática da região de Blumenau por uma das autoras deste artigo. $O$ curso teve os seguintes objetivos: (i) analisar, com os professores, a conceituação de cidadania e a abordagem dos documentos oficiais do governo sobre o tema; (ii) apresentar uma proposta de atividades que contribuam no aprendizado de conceitos matemáticos, envolvendo situações aplicadas ao cotidiano, as quais auxiliem na construção da cidadania dos estudantes; (iii) instigar o professor a elaborar e aplicar novas propostas de atividades que contribuam para o exercício da cidadania dos estudantes.

O curso teve duração de 20 horas/aula, sendo 12 horas presenciais e oito horas a distância, sendo que essa parte a distância foi realizada para que o professor participante do curso pudesse aplicar uma das atividades com seus estudantes, anotando os resultados obtidos para posterior discussão.

\section{Refletindo a aplicação de uma das atividades}

Nesta seção serão apresentados os resultados da aplicação da atividade "Áreas interditadas após o deslizamento de 2008 e determinante". Dentre todas as atividades propostas, essa foi a que, durante o curso ministrado, despertou maior interesse dos participantes. Uma cursista aplicou a atividade em uma turma de Ensino Médio durante o decorrer do curso, sendo que, as considerações dos alunos relativas às ações desenvolvidas foram discutidas pelos participantesem um dos encontros do curso. Além disso, essa atividade também foi aplicada por uma das autoras do artigo em suas turmas de Ensino Médio, tendo como resultados a intensa participação dos

\footnotetext{
${ }^{1}$ Para este curso o mapa utilizado foi encontrado no Anexo II do Decreto de Lei no 9151/2010 de Blumenau com a redação dada pelo Decreto 9353/2011, obtido no site www.blumenau.sc.gov.br, no link legislação. Desta forma, na escola de Ascurra o mapa analisado foi o do Decreto de Lei no 9151/2010. Já para a aplicação com os cursos integrados, que foi realizada no ano de 2013, buscou-se um mapa mais recente, sendo utilizado o mapa do Anexo II do Decreto de Lei de Blumenau no 9853/2012, obtido no site www.blumenau.sc.gov.br, no link legislação.
}

R. B. E. C. T., vol 8, núm. 4, set-dez.2015 ISSN - 1982-873X

DOI: Em andamento. 
alunos. Essa atividade foi a que mais envolveu aplicações em sala de aula e discussões posteriores, e estes fatos devem-se, possivelmente, por ela explorar a discussão de uma problemática vivenciada na região em que todos residem.

Como mencionado, essa atividade foi aplicada em três ocasiões: em uma turma de segundo ano do Ensino Médio de uma escola de Ascurra, em uma turma de estudantes do curso técnico integrado em química e, em uma turma de estudantes do curso técnico integrado em vestuário do Instituto Federal de Santa Catarina Câmpus Gaspar, instituição na qual uma das autoras do artigo trabalha.

A atividade pretendia corroborar com o que Skovsmose chama de uma educação crítica (EC), pois, segundo o autor,

"[...] na EC, é essencial que os problemas se relacionem com situações $e$ conflitos sociais fundamentais, e é importante que os estudantes possam reconhecer os problemas como "seus próprios problemas", de acordo com ambos os critérios subjetivo e objetivo da identificação do problema da EC. (Skovsmose, 2001, p.24)"

Como a atividade foi aplicada em turmas de estudantes que vivenciaram o desastre de 2008, por residirem em municípios também atingidos pelo evento, o tema faz parte das preocupações sociais existentes na comunidade na qual eles estão inseridos, o que motivou o estudo desse tema pelos mesmos.

Vamos, a partir de agora, fazer uma breve reflexão sobre o desenvolvimento da atividade nas três turmas em que ela foi aplicada.

No município de Ascurra, a professora explorou o mapa, sua legenda e escala com os estudantes. A dificuldade apresentada pelos estudantes nessa atividade foi a questão da escala, uma vez que $1,5 \mathrm{~cm}$ equivalem a $2000 \mathrm{~m}$. No desenvolvimento da atividade foi necessário que a professora lembrasse os estudantes de que as subdivisões dessa escala deveriam ser feitas para facilitar e para se aproximarem da coordenada x e y corretas. (lembrar que entre o 2,9 e 4,9 temos o 3,9, por exemplo).

Essa mesma dificuldade foi apresentada pelos estudantes de uma das autoras deste artigo na aplicação dessa atividade. Com os cursos integrados, a professora entregou um roteiro de atividade que consistia no mapa e na explicação da atividade a ser desenvolvida (análise do mapa e cálculo das áreas interditadas no mapa utilizando determinantes). Diferentemente da aplicação pela professora de Ascurra, que delimitou os triângulos a serem calculados, a professora do Instituto deixou que os estudantes escolhessem os vértices do triângulo para o cálculo do determinante. Assim, cada trabalho teve um cálculo diferente. (ver figura 3)

122 DOI: Em andamento. 


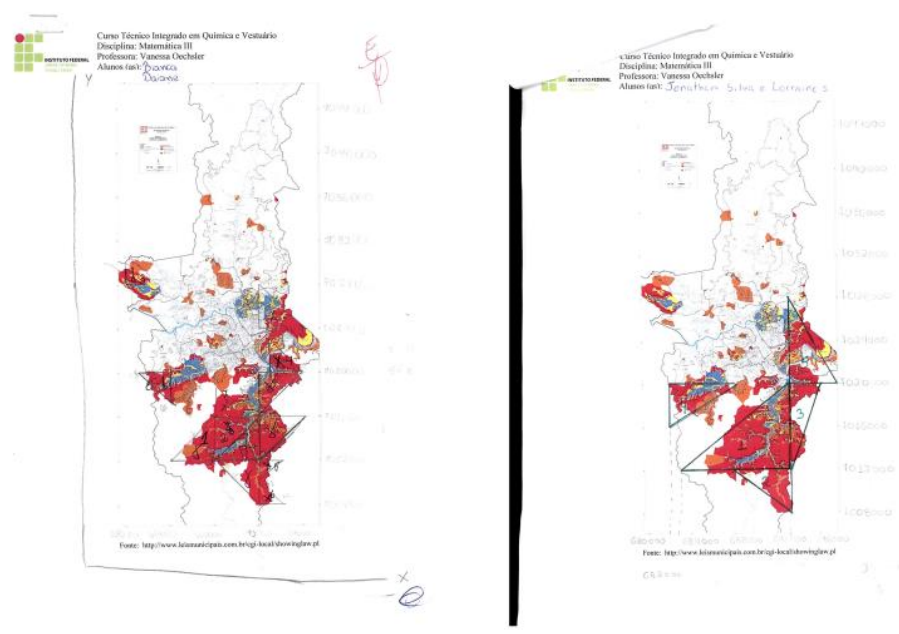

Figura 3: Escolha dos vértices dos triângulos em dois trabalhos do curso técnico integrado em química

por mostrar uma aplicação para o cálculo de determinantes. "Nos mostrou como usar determinantes no cotidiano usando valores reais. Mostrou onde a gente pode aplicar." (comentário de um grupo do curso técnico integrado em vestuário). No entanto, uma das dificuldades apresentadas pelos grupos foide efetuar o cálculo do determinante com números com muitos algarismos. "Foi bem dinâmico, deu pra aprender bastante, porém os números grandes dificultaram o resultado." (depoimento de um grupo do curso técnico integrado em vestuário). Realmente, ao se trabalhar com uma situação prática, tais dificuldades podem ocorrer. Mesmo com o uso de calculadora, os estudantes sentiram dificuldades em efetuar os cálculos solicitados. Pensa-se que, para uma próxima aplicação dessa atividade, os estudantes possam utilizar como apoio uma planilha eletrônica que auxilie no cálculo do determinante, uma vez que o intuito da atividade vai muito além disso, ela pretende mostrar uma aplicação do assunto e discutir essa aplicação no contexto em que os estudantes vivem.

Até esta parte da atividade aqui relatada, abordou-se apenas uma aplicação da matemática em uma situação concreta, o que é defendido também pela Matemática Aplicada. A partir daí, pode surgir uma dúvida: qual a diferença entre Educação Crítica e Matemática Aplicada? Percebese que, muitas vezes, confunde-se a Educação Crítica com a Matemática Aplicada, pois para se refletir criticamente sobre um assunto, usa-se a Matemática aplicada a um problema real. No entanto, de acordo com Skovsmose (2001a, p.23, grifo do autor) na

"[...]Mathematic applicable [Matemática aplicável] é difícil encontrar uma plataforma para um autêntico diálogo professor-estudante. Os manuais contêm exemplos de modelagem matemática, e o processo de educação deve pelo menos de acordo com a exposição caminhar de um exemplo preparado para outro exemplo preparado. O que os estudantes têm de fazer é calcular, encontrar soluções e resolver problemas já bem definidos." 
Nessa passagem, percebe-se que a Matemática Aplicada nem sempre é crítica, pois o estudante pode simplesmente resolver a situação apresentada sem discuti-la com o professor e os colegas. Até essa parte da atividade apresentada, podemos dizer que ela é apenas uma forma de Matemática Aplicada, uma vez que o estudante utilizou o conteúdo matemático apenas para calcular a quantidade de áreas interditadas para moradia em Blumenau, sem refletir sobre que implicações isso tem na vida da sociedade.

Do que vimos até aqui, a Educação Crítica não se limita à aplicação da Matemática para resolver problemas do cotidiano, ela envolve a discussão dos problemas e a análise das respostas para eles obtidas. Skovsmose (2001) vai ainda além, citando que os problemas discutidos criticamente não devem pertencer à realidade do faz de conta, mas devem fazer sentido na realidade do estudante.

Ainda dentro desse contexto, a Educação Crítica defende o trabalho com problemas do cotidiano, utilizando os seguintes critérios:

“1) Deveria ser possivel para os estudantes perceber que o problema é de importância. Isto é, o problema deve ter relevância subjetiva para os estudantes. Deve estar relacionado a situações ligadas às experiências deles.

2) O problema deve estar relacionado a processos importantes na sociedade.

3) De alguma maneira e em alguma medida, o engajamento dos estudantes na situação-problema e no processo de resolução deveria servir como base para um engajamento político e social (posterior)." (Skovsmose, 2001a, p.34)

Nessa citação, percebe-se que o exemplo trabalhado neste artigo tem características de Educação Crítica, pois é de relevância social, uma vez que a tragédia de 2008 no Vale do Itajaí fez parte da vida da maioria dos estudantes que desenvolveu a atividade.

Por este motivo, a discussão da atividade não foi encerrada apenas com o cálculo da área do determinante. Após essa etapa matemática, os estudantes foram instigados a discutir as questões de critérios para a construção de imóveis em uma cidade, o porquê de algumas pessoas construírem em locais de risco, quais as medidas que devem ser tomadas para que as pessoas não construam em locais de risco, entre outras.

Com relação à aplicação desta atividade na discussão sobre cidadania, observou-se, nas respostas apresentadas pelos estudantes, em todas as turmas em que essa atividade foi aplicada, uma conscientização sobre o tema. Através dos trabalhos, percebeu-se que os estudantes verificaram que, para se construir na cidade, deve-se ter a autorização de um engenheiro, que verificará as condições do terreno e da região e também da prefeitura da cidade, que já tem o 
mapeamento das áreas de risco e pode instruir a população quanto à construção em locais apropriados. (Figura 4)

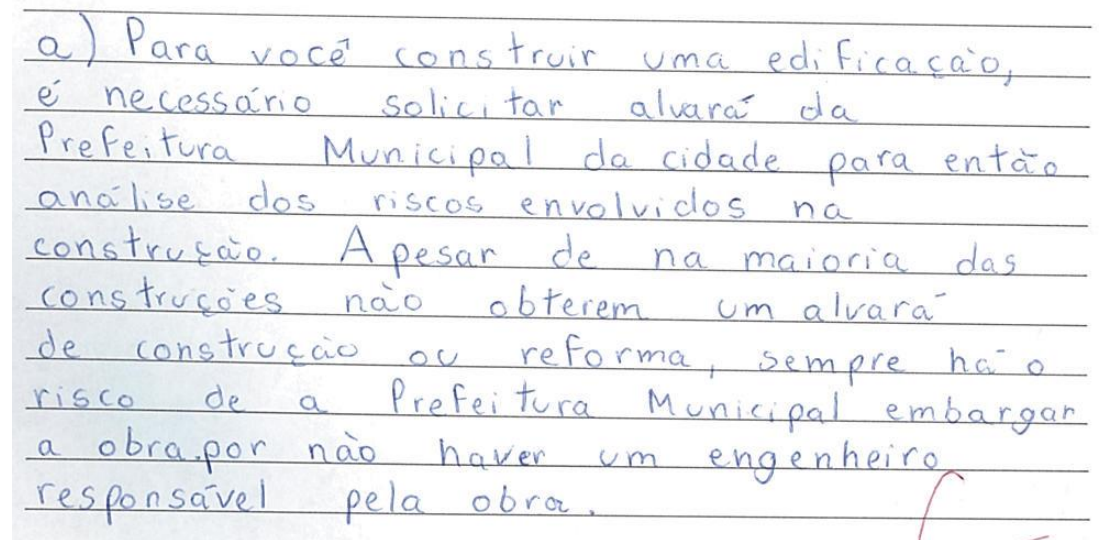

Figura 4: Análise de um grupo de alunos do curso técnico integrado em química sobre a pergunta: "Você sabe quais os critérios levados em consideração para se mapear os locais de construção na cidade?"

Nas análises, os estudantes destacaram que, geralmente, quem constrói em locais de risco são pessoas que não possuem condições financeiras para adquirir imóveis em outros locais. De acordo com os estudantes, as condições de moradia desses locais são precárias "sem nenhum desenvolvimento do saneamento básico". Pensando em ações para sanar esse problema, os estudantes destacaram que a população deve se conscientizar para não construir nesses locais e a Defesa Civil pode auxiliar nessa conscientização. (Figura 5)

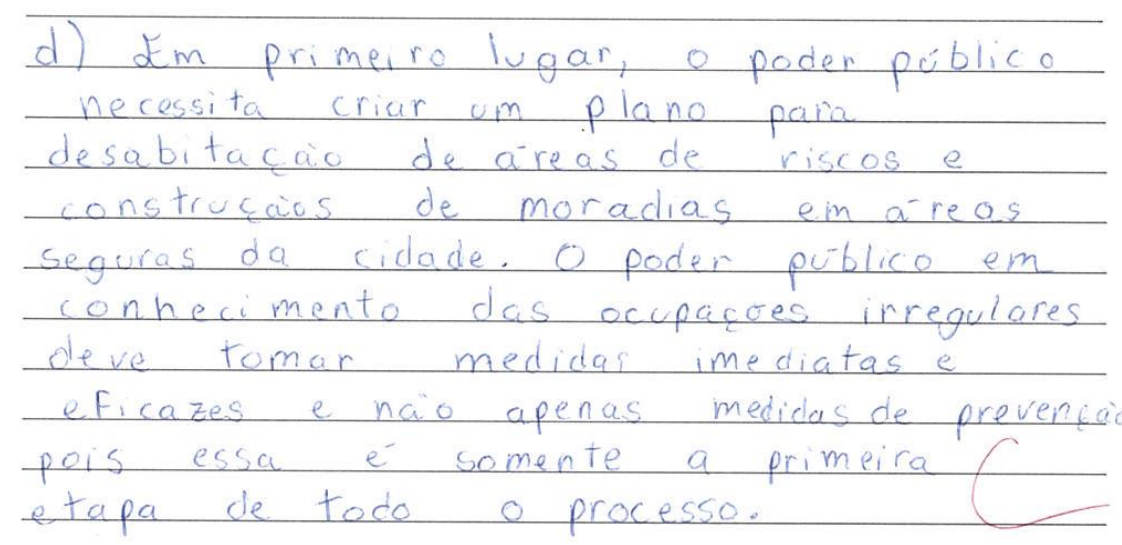

Figura 5: Análise de um grupo de alunos do curso técnico integrado em química sobre a pergunta "O que as pessoas e o poder público devem fazer para impedir a construção em locais de risco?"

Além da conscientização da população, uma nova discussão pode ser suscitada: a construção de moradias populares, uma vez que essa foi uma prática comum na região após o desastre de 2008 e, alguns desses estudantes que participaram das atividades, inclusive moram 
nesses condomínios. Essa poderia ser uma alternativa a ser discutida com o poder público para retirar as pessoas que moram em áreas de risco.

Como resultado desta atividade, os professores que a realizaram com os estudantes apontaram que estes ficaram espantados com o tamanho da área que está em estudo no qual ocorre risco de deslizamentos em Blumenau. A partir de tal relato, percebe-se que com este tipo de atividade conseguiu-se atingir um dos objetivos da pesquisa que é fazer com que o estudante perceba a Matemática como uma ferramenta para se entender o mundo em que se vive. Ao calcular a quantidade de áreas de risco na cidade, o estudante percebe que muitas regiões estão em perigo, e através de discussões em sala de aula, como as promovidas nesta atividade, é possivel fazer com que o estudante reflita sobre as causas desse problema e busque algumas soluções para conscientizar a população acerca do tema.

\section{Algumas considerações}

Neste artigo defendeu-se uma Educação Crítica em que os estudantes sejam incentivados a exercer sua cidadania. E, como aponta Pinheiro (2005, p.62), "Ao sublinhar uma educação voltada para tais questões, não se enfatiza o abandono do conteúdo matemático nas situações de ensino, mas o resgate de sua dimensão crítica". Dessa forma, em nenhum momento deste artigo discute-se a possibilidade de se abandonar o currículo matemático, o que pode ser observado através das atividades propostas, uma vez que ela foram criada para abordar um conteúdo do Ensino Médio: funções e determinantes. O que se defende é o estudo do currículo, de forma que, ao se trabalhar os assuntos nele contemplados, os estudantes sejam instigados a refletir, criticar e buscar formas de utilizá-los (utilizar tais assuntos) em seu cotidiano de forma a modificar a realidade da sociedade.

Nesse sentido, este artigo apresentou duas atividades para subsidiar o professor em sala de aula na formação de cidadãos mais críticos, atividades essas baseadas em discussões na área da Educação Matemática Crítica. Ressalta-se que outras pesquisas que possam subsidiar a prática do professor na formação de cidadãos ainda são necessárias, tanto no que tange à criação de novas ideias de atividades quanto no estudo da realização das atividades em si, apontando qual a aceitação dos estudantes em relação a elas.

\section{Referências}

BLUMENAU. Decreto no 9363, 31 março 2011. Substitui o anexo ii do decreto no 9151, de 12 de abril de 2010, que "dispõe sobre as áreas com restrição de uso e ocupação do solo e dá outras providências". Disponível em: <http://www.leismunicipais.com.br/cgi-local/showinglaw.pl> Acesso em: 18 ago. 2011. 
BRASIL. Lei de Diretrizes e Bases da Educação Nacional. Lei no 9394, de 20 de dezembro de 1996. Estabelece as diretrizes e bases da educação nacional. Brasília, DF, 1996.

BRASIL. Secretaria de Educação Básica. Parâmetros Curriculares Nacionais: Ensino Médio. Brasília: MEC/SEB, 2000.

FIRER, M. Matemática Multimídia: determinantes e polígonos - guia do professor. Disponível em: <http://m3.ime.unicamp.br/recursos/1227> Acesso em: 05 out.2015

GIOVANNI, J.R; BONJORNO, J.R Matemática Completa. 2. ed. renov. São Paulo: FTD, 2005. v.1 HOUAISS, A.; VILLAR, M. S.; FRANCO, F. M. M. Dicionário Houaiss da Língua Portuguesa. Rio de Janeiro: Objetiva, 2009.

IEZZI, G.; HAZZAN, S. Fundamentos de Matemática Elementar: sequências, matrizes, determinanes, sistemas. V.4,7.ed, São Paulo: Atual, 2004.

MARSHALL, T.H. Cidadania, classe social e status. Rio de Janeiro: Zahar Editores, 1967.

SIEBERT, C. (Dês)controle urbano no vale do Itajaí. In: FRANK, B.; SEVEGNANI, L. (orgs). Desastre de 2008 no vale do Itajaí. Água, gente e política. Blumenau: Agência de Água do Vale do Itajaí, 2009. p.38-51

OXFORD. The concise Oxford Dictionary osPolitcs. 2a ed. Oxford University Press: 2003.

PINHEIRO, N. A. M. Educação crítico-reflexiva para um ensino médio científico-tecnológico: a contribuição do enfoque CTS para o ensino-aprendizagem do conhecimento matemático. 2005. Tese (Doutorado) - Universidade Federal de Santa Catarina, Florianópolis, 2005. Disponível em: <http://antiga.ppgect.ufsc.br/teses/03/Tese.pdf> Acesso em: 21 fevereiro 2011.

MATTEDI, Marcos Antônio. et. al. C. O desastre se tornou rotina...In: FRANK, B.; SEVEGNANI, L. (orgs). Desastre de 2008 no vale do Itajaí. Água, gente e política. Blumenau: Agência de Água do Vale do Itajaí, 2009. p.13-21

SKOVSMOSE, O. Educação Matemática versus Educação Crítica. In: SKOVSMOSE, O. Educação Matemática Crítica: a questão da democracia. 3 ed. Campinas: Papirus, 2001a, p.13-36 Competência democrática e o conhecer reflexivo na matemática. In: SKOVSMOSE, O. Educação Matemática Crítica: a questão da democracia. 3 ed. Campinas: Papirus, 2001b, p.65-96.

Vanessa Oechsler - Doutoranda em Educação Matemática pela Universidade Estadual Paulista Júlio de Mesquita Filho (UNESP) de Rio Claro e Mestre em Ensino de Ciências Naturais e Matemática pela Universidade Regional de Blumenau (FURB). Docente de Matemática do Instituto federal de Santa Catarina (IFSC) - Câmpus Gaspar. E-mail: vanessa.oechsler@ifsc.edu.br 
Rosinéte Gaertner - Doutora em Educação Matemática pela Universidade Estadual Paulista Júlio de Mesquita Filho (UNESP) de Rio Claro. Docente voluntária da Universidade Regional de Blumenau (FURB). E-mail: rogaertner@gmail.com 